\title{
Serous Adenocarcinoma of Fallopian Tubes: Histological and Immunohistochemical Aspects
}

Natalia Hyriavenko · Mykola Lyndin Kateryna Sikora ${ }^{1}$. Artem Piddubnyi Ludmila Karpenko • Olha Kravtsova Dmytrii Hyriavenko ${ }^{2}$ Olena Diachenko ${ }^{2}$. Vladyslav Sikora Anatolii Romaniuk

Department of Pathology, Sumy State University, Sumy; ${ }^{1}$ Sumy Regional Clinical Perinatal Center, Sumy; ${ }^{2}$ Sumy State University, Sumy, Ukraine

Received: January 16, 2019

Revised: March 15, 2019

Accepted: March 20, 2019

\section{Corresponding Author}

Natalia Hyriavenko, MD, PhD

Department of Pathology, Sumy State University,

st. Privokzalnaya, 31, m. Sumy 40022, Ukraine

Tel: +380-997466578

Fax: $+380-542334058$

E-mail: n.gyryavenko@med.sumdu.edu.ua

\begin{abstract}
Background: Although primary cancer of the fallopian tubes is a relatively rare type of tumor in female reproductive organs, its mortality is quite high. It is important to identify molecular and biological markers of this malignancy that determine its specific phenotype. Methods: The study was carried out on samples received from 71 female patients with primary cancer of the fallopian tubes. The main molecular and biological properties, including hormone status (estrogen receptor [ER], progesterone receptor [PR]), human epidermal growth factor receptor (HER2)/neu expression, proliferative potential (Ki-67), apoptosis (p53, Bcl-2), and pro-angiogenic (vascular endothelial growth factor) quality of serous tumors were studied in comparison with clinical and morphological characteristics. Results: ER and PR expression is accompanied by low grade neoplasia, early clinical disease stage, and absence of lymphogenic metastasis $(p<.001)$. HER2/neu expression is not typical for primary cancer of the fallopian tubes. Ki-67 expression is characterized by an inverse correlation with ER and PR $(p<.05)$ and is associated with lymphogenic metastasis $(p<.01)$. p53+ status correlates with high grade malignancy, tumor progression, metastasis, negative ER/PR $(p<$ .001 ), and negative $\mathrm{Bcl}-2$ status $(\mathrm{p}<.05)$. Positive $\mathrm{Bcl}-2$ status is positively correlated with $\mathrm{ER}$ and PR expression and low grade malignancy. Conclusions: Complex morphologic (histological and immunohistochemical) study of postoperative material allows estimation of the degree of malignancy and tumor spread to enable appropriate treatment for each case.
\end{abstract}

Key Words: Carcinoma, serous; Neoplasms; Fallopian tubes; Estrogen receptor; Progesterone receptor; Ki-67; HER2/neu; p53; Bcl-2; Vascular endothelial growth factor
Primary cancer of the fallopian tubes (PCFT) has the lowest incidence of tumors of the female reproductive organs, but its mortality is quite high. ${ }^{1}$ It was first described in a small number of patients as sporadic observations. The cause, frequency, diagnosis, prevention, and treatment of PCFT are insufficiently illuminated in the modern medical literature. The incidence of malignant tumors of the fallopian tubes (FT) ranges from $0.14 \%$ to $1.8 \%$ among all malignant tumors of the female reproductive system. ${ }^{2-5}$ While it is difficult to identify the initial tumor process of tubo-ovarian tumors, FT malignant tumors are often regarded as a type of ovarian cancer. Consequently, these tumors are much more frequent in gynecologic practice. ${ }^{6,7}$ This causes significant discrepancies regarding reports of PCFT morbidity, which undoubtedly depends on the quality of morphologic diagnosis.

Practically, FT carcinomas are found more frequently in oncogynecology. Moreover, they serve as the primary source for serous and mucinous tumors of the ovaries and peritoneum. ${ }^{8-11}$ Increased oncologic awareness and improved diagnostic methods have led to a relative increase in the PCFT detection rate in recent years. ${ }^{12}$ The main prognostically important criteria remain tumor clinical stage and their degree of malignancy. ${ }^{13,14}$ The rarity of PCFT has made it impossible to identify significant predictive factors thus far. Identification of tumor markers in PCFT tissue may provide important diagnostic and prognostic information about the biological properties of this neoplasm.

Information about tumor hormonal status (estrogen receptor $[\mathrm{ER}]$ and progesterone receptor $[\mathrm{PR}]$ ), proliferative potential (Ki-67), anti-apoptotic properties ( $\mathrm{p} 53$ and $\mathrm{Bcl}-2$ ), and ability to stimulate angiogenesis (vascular endothelial growth factor [VEGF]) will undoubtedly serve as the basis for a pathophysiologic understanding of the molecular properties of FT cancer. Further information may allow identification of new target therapeutic methods for PCFT. Investigation of these tumor parameters is the aim of this study.

\section{MATERIALS AND METHODS}

The material was collected from Sumy Regional Pathology 
Clinical Center and Sumy Regional Clinical Oncology Center. Written informed consent to investigate tissue was obtained from patients. The Bioethics Commission of the Medical Institute of Sumy State University approved the experimental protocol (No. 8 from 29.04.2016).

The research was performed on surgical material obtained from 71 female patients with PCFT. Pathologic findings were identified using SEE-FIM protocols of FT tissue examination. Determination of the primacy of FT lesions was based on the following criteria: main tumor focus localized in the FT with spread from the endosalpinx for ovary and/or uterus involvement; FT contained more neoplastic mass tissue than other sites; border between normal and affected (neoplastic) epithelium of the tube was visualized; no malignant neoplasms of other localizations.

Hematoxylin-eosin stained tissue sections of 5- $\mu \mathrm{m}$ thickness allowed determination of the histogenesis, degree of tumor malignancy, depth of invasion, spread into pelvic organs, and presence of metastases in regional lymph nodes.

For immunohistochemical study, 4- $\mu \mathrm{m}$ sections were made from paraffin blocks, subjected to standard deparaffinization, dehydrated in xylene and ethanol of graded concentrations, and mounted on 3-aminopropyltriethoxysilane-coated slides. Antigen retrieval was carried out in a water-bath at $97^{\circ} \mathrm{C}-98^{\circ} \mathrm{C}$. Antigen-antibody reaction was visualized using the Ultra Vision Quanto Detection System HRP DAB Chromogen (Thermo Fisher Scientific, Waltham, MA, USA), which included blocking endogenous peroxidase activity, blocking nonspecific back- ground staining using the Ultra V block, and enhancing the reaction by Primary Antibody Amplifier Quant. The final visualization was carried out with diaminobenzidine with additional nuclei counterstaining with Modified Mayer's Hematoxylin (Thermo Fisher Scientific).

To exclude influences of tumor histogenesis on the immunophenotype of cancer cells, the presence of serous adenocarcinoma of the FT (SAcFT) was a criterion for inclusion in the studied group to investigate its molecular-biological markers. All other types (mucinous, squamous, etc.) of PCFT were excluded. While there were few excluded cases, they may have influenced the obtained results. The antibody panel specified in Table 1 was used for this research (Thermo Fisher Scientific).

Obtained specimens were examined using a microscope with digital camera Zeiss AxioCam ERs 5s and ZEN 2 (blue edition) software (Zeiss, Jena, Germany).

Data processing was carried out using Microsoft Excel 2010 with the application Attestat 12.0.5. Estimation of probable differences between comparable indicators was carried out using the Student's t-test. Detection and evaluation of the links between indicators was carried out using the nonparametric Spearman correlation coefficient (r). A p-value of 0.05 and $95 \%$ confidence interval was considered statistically significant.

\section{RESULTS}

Archive data from the Sumy Regional Pathology Clinical Center and Sumy Regional Clinical Oncology Center indicated

Table 1. Antibody panel used for immunohistochemical research

\begin{tabular}{|c|c|c|c|c|c|}
\hline Antibody & Immunized animal & Clone & Dilution & Pattern & Evaluation features \\
\hline $\mathrm{ER}$ & Rabbit & SP1 & $1: 200$ & Nucleus & \multirow{2}{*}{$\begin{array}{l}\text { According to the recommendations of D.C. Allred and taking into account } \\
\text { the proportion of colored nuclei and the intensity of their staining }\end{array}$} \\
\hline PR & Rabbit & YR85 & $1: 150$ & Nucleus & \\
\hline HER2/neu & Rabbit & SP3 & $1: 100$ & Membrane & $\begin{array}{l}\text { In points (from } 0 \text { to 3), according to the manufacturer's recommendations } \\
\text { and taking into account the completeness and intensity of membrane } \\
\text { staining }\end{array}$ \\
\hline $\mathrm{Ki}-67$ & Rabbit & SP6 & $1: 100$ & Nucleus & $\begin{array}{l}0 \text { point: negative reaction } \\
1 \text { point: weakly positive reaction }(n=0 \%-30 \%) \\
2 \text { points: moderately positive reaction }(30 \%<n<60 \%) \\
3 \text { points: strong positive reaction }(n>60 \%)\end{array}$ \\
\hline p53 & Mouse & SP5 & $1: 100$ & Nucleus & $\begin{array}{l}\text { Weak reaction (10-25\% of positively stained tumor cells), moderate positive } \\
\text { reaction (25\%-50\%) and strong positive reaction (> 50\%) }\end{array}$ \\
\hline $\mathrm{Bcl}-2$ & Mouse & 100/D5 & $1: 100$ & Cytoplasm & $\begin{array}{l}\text { Weak expression }(1+) \text { : weak cytoplasmic staining of more than } 10 \% \text { of } \\
\text { tumor cells } \\
\text { Moderate }(2+) \text { : staining of average intensity more than } 10 \% \\
\text { Strong }(3+) \text { : intense staining of more than } 10 \% \text { of tumor cells }\end{array}$ \\
\hline VEGF & Rabbit & Polyclon & $1: 200$ & $\begin{array}{l}\text { Cytoplasm and } \\
\text { membrane }\end{array}$ & $\begin{array}{l}0 \text { points: absence of cytoplasmic expression } \\
1 \text { point: weak cytoplasmic staining less than } 10 \% \text { of cells } \\
2 \text { points: weak or moderate expression in } 10 \%-50 \% \text { of cells } \\
3 \text { points: strong or moderate expression in more than } 50 \% \text { of cells }\end{array}$ \\
\hline
\end{tabular}

ER, estrogen receptor; PR, progesterone receptor; HER2, human epidermal growth factor receptor; VEGF, vascular endothelial growth factor. 
that PCFT accounted for $1.13 \%$ of malignant neoplasms of the female reproductive system and $4.36 \%$ of malignant neoplasms of the uterine appendages (peak incidence was between 50 and 69 years). FT carcinomas were predominantly localized on one side, and bilateral involvement of tubes was detected in only $16.9 \%$ of cases. The tumor process involved the ampulla segment more often $(87.3 \%)$ than the isthmus (7.1\%) or infundibulum (5.6\%). In most cases, FT neoplasias (60.6\%) were identified at stages I-II (Table 2).

Neoplastic spread outside the FT was found in $66.2 \%$ of women during diagnosis. Metastatic tumor dissemination into the omentum, peritoneum, ovaries, and regional lymph nodes did not depend on the size of the primary focus in the FT. Nevertheless, metastases in iliac and lumbar lymph nodes were detected in $26.8 \%$ of cases.

Table 2. Division of PCFT cases according to FIGO classification

\begin{tabular}{|c|c|}
\hline Stage & No. of patients with PCFT (\%) \\
\hline 0 & - \\
\hline । & $24(33.8)$ \\
\hline $\mathrm{A}-\mathrm{T}_{1 \mathrm{a}} \mathrm{N}_{0} \mathrm{M}_{0}$ & $5(7.0)$ \\
\hline $\mathrm{IB}-\mathrm{T}_{1 \mathrm{~b}} \mathrm{~N}_{0} \mathrm{M}_{0}$ & $8(11.3)$ \\
\hline $\mathrm{IC}-1_{1 \mathrm{c}} \mathrm{N}_{0} \mathrm{M}_{0}$ & $11(15.5)$ \\
\hline$\|$ & $19(26.8)$ \\
\hline$\| \mathrm{A}-\mathrm{T}_{2 \mathrm{a}} \mathrm{N}_{0} \mathrm{M}_{0}$ & $10(14.1)$ \\
\hline$\| B-T_{2 b} N_{0} M_{0}$ & $3(4.2)$ \\
\hline$\| C-T_{2 c} N_{0} M_{0}$ & $6(8.5)$ \\
\hline III & $28(39.4)$ \\
\hline$\| \mathrm{A}-\mathrm{T}_{3 \mathrm{a}} \mathrm{N}_{0} \mathrm{M}_{0}$ & $2(2.8)$ \\
\hline\|\|$B-T_{3 b} N_{0} M_{0}$ & $5(7.0)$ \\
\hline$\| I C-T_{3 c} N_{0} M_{0}$ & $2(2.8)$ \\
\hline$\| I C-T_{1-3} N_{1} M_{0}$ & $19(26.8)$ \\
\hline $\mathrm{IV}-\mathrm{T}_{1-3} \mathrm{~N}_{0-1} \mathrm{M}_{1}$ & - \\
\hline Total & $71(100)$ \\
\hline
\end{tabular}

PCFT, primary cancer of the fallopian tubes; FIGO, International Federation of Gynecology and Obstetrics.
Our histologic study showed that the overwhelming majority of malignant neoplasms of the FT were SAcFT (93.0\% of cases) (Fig. 1). Mucinous (2.8\%), clear cell (2.8\%), and squamous cell carcinomas (1.4\%) were quite rare.

A total of $88.4 \%$ of SAcFT cases showed a high degree of malignancy (low [G3] and moderately differentiated [G2]). Their metastases were more often present in regional lymph nodes (28.2\%), omentum, peritoneum (11.3\%), and ovaries (5.6\%).

Immunohistochemical study showed variable expression of ER and PR (Fig. 2A, B): ER+PR+, 62.1\%; ER+PR-, 21.2\%. Strong expression of ER and PR in SAcFT correlated with welldifferentiated tumors (low grade cancer) and initial clinical stages of disease $(\mathrm{p}<.001)$. The presence of metastases in lymph nodes was accompanied by significantly lower expression of ER ( $\mathrm{p}<$ $.001)$ and PR $(\mathrm{p}<.001)$ in cancer cells compared to cases without metastases $(\mathrm{p}<.05)$.

Human epidermal growth factor receptor (HER2)/neu overexpression was not typical for SAcFT $(80.9 \%$ of tumors were receptor-negative). Nevertheless, most neoplastic FT cells (55.0 $0_{ \pm}$ 12.2\%) expressed Ki-67 receptors (Fig. 2C, D). Table 3 shows the division of patients by Ki-67 expression level.

Tumor cell proliferation was characterized by an inverse relationship with steroid hormone expression $(\mathrm{p}<.05)$. In groups with positive receptor status ( $\mathrm{ER}+\mathrm{PR}+), \mathrm{Ki}-67$ overexpression (more than 60\%) was detected in only $46.3 \%$ of cases. Conversely, tumors with completely negative ER and PR or with only ER positivity had significantly higher proliferative activity $(63.4 \%$ and $71.4 \%$, respectively). There were no differences in Ki-67 expression, clinical tumor stage, or degree of differentiation ( $\mathrm{p}>.05$ ).

In 13 cases (19.7\%), a negative reaction was detected for the pro-apoptotic protein p53 (Fig. 2F). Fifty-three cases of SAcFT (80.3\%) were p53-positive. Among them, nine cases (13.6\%) were weakly positive, 13 cases $(19.7 \%)$ were moderately posi-
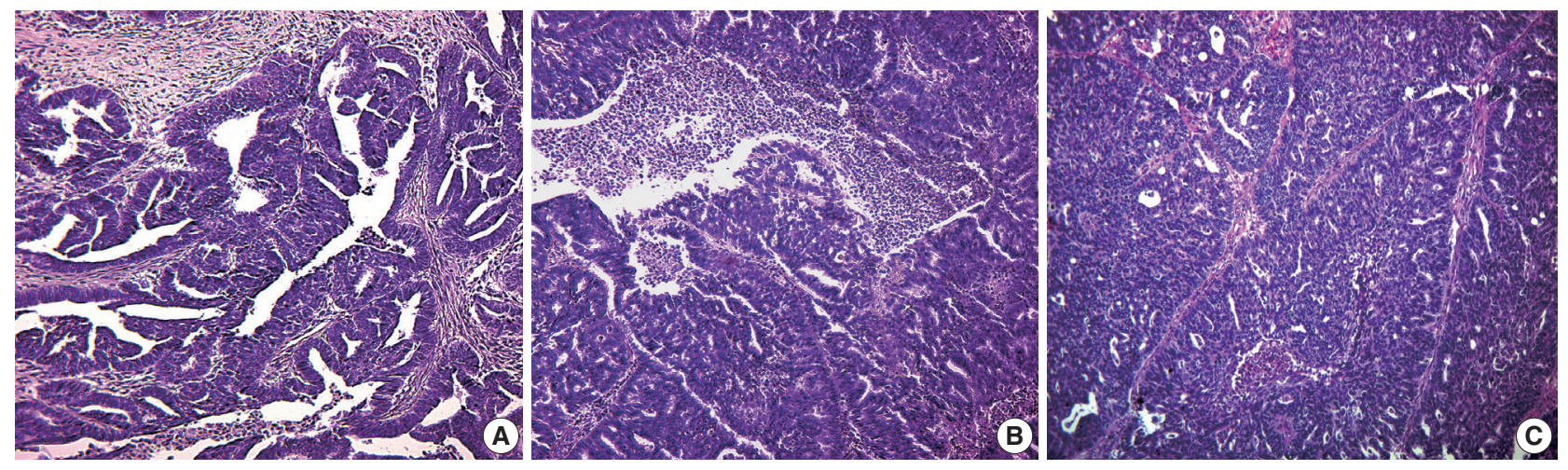

Fig. 1. Serous adenocarcinoma of the fallopian tube. (A) $G_{1}$ (low degree of malignancy). (B) $G_{2}$ (high degree of malignancy). (C) $G_{3}$ (high degree of malignancy). 

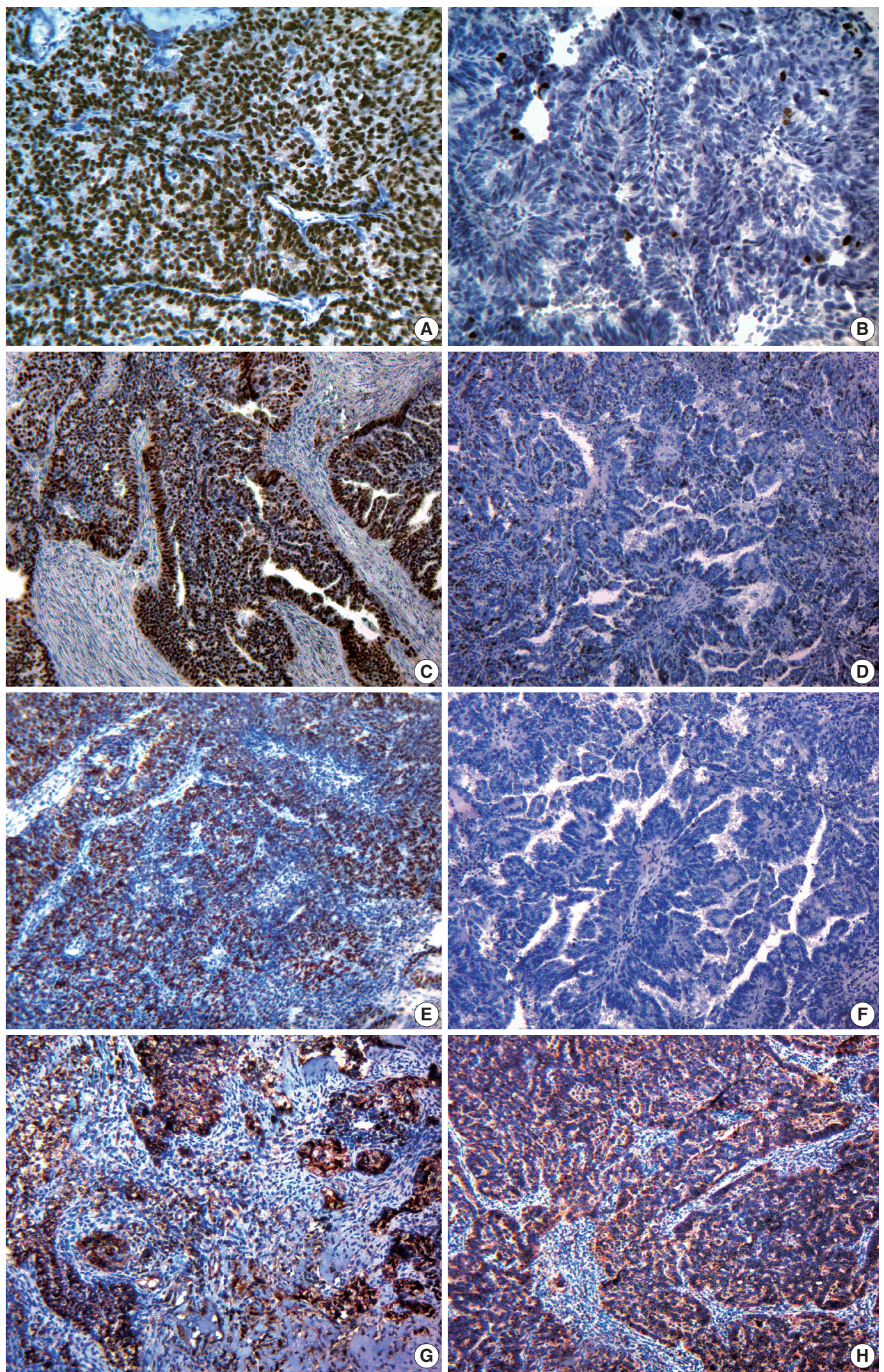

Fig. 2. Serous adenocarcinoma of the fallopian tube. Immunohistochemical study of estrogen receptors (A, B), Ki-67 (C, D), p53 (E, F), and vascular endothelial growth factor $(G, H)$ expression. 
Table 3. Division of female patients by level of Ki-67 expression in SAcFT tissue

\begin{tabular}{lc}
\hline Average index of proliferation (\%) & No. of female patients with SAcFT (\%) \\
\hline 0 & 0 \\
$0-30$ & $12(18.2)$ \\
$30-60$ & $18(27.3)$ \\
$>60$ & $36(54.5)$ \\
\hline
\end{tabular}

SAcFT, serous adenocarcinoma of the fallopian tubes.

Table 4. Results of p53 expression study in SAcFT depending on prevalence, presence of lymphogenous metastases, and degree of malignancy

\begin{tabular}{lc}
\hline Evaluation's criteria & Average No. of p53 (\%) \\
\hline Disease stage according to FIGO classification & \\
I & $10.5 \pm 2.2$ \\
III & $46.8 \pm 5.2$ \\
Presence of lesion in regional lymph nodes & $71.7 \pm 3.9$ \\
$\mathrm{~N}_{0}$ & \\
$\mathrm{~N}_{1}$ & $29.7 \pm 3.6$ \\
Degree of tumor differentiation & $80.6 \pm 2.7$ \\
$\mathrm{G}_{1}$ & \\
$\mathrm{G}_{2}$ & $5.6 \pm 2.4$ \\
$\mathrm{G}_{3}$ & $35.6 \pm 6.2$ \\
\hline
\end{tabular}

SAcFT, serous adenocarcinoma of the fallopian tubes; FIGO, International Federation of Gynecology and Obstetrics.

tive, and 31 cases (47\%) were strongly positive (Fig. 2E). The presence of these receptors in tumor tissue was found in patients of all clinical stages. Strong correlations were identified between the presence of $\mathrm{p} 53$ and clinical stage $(\mathrm{r}=0.77, \mathrm{p}<.001)$, as well as between $\mathrm{p} 53$ and degree of differentiation $(\mathrm{r}=0.58, \mathrm{p}<$ .001) (Table 4). Significantly higher p53 expression was identified in the group of patients with metastases $(80.6 \% \pm 2.7 \%)$ compared to those without metastases $(29.7 \% \pm 3.6 \%)$.

A total of $81.8 \%$ of SAcFT cases were Bcl-2-positive. Most of them (96.3\%) also had ER and PR (71.4\%) expression. Positive correlations were identified between $\mathrm{Bcl}-2$ and expression of ER $(r=0.84, p<.001)$ and $P R(r=0.69, p<.001)$. In contrast to $\mathrm{p} 53$, a moderate negative correlation was identified between $\mathrm{Bcl}-2$ and clinical disease stage $(\mathrm{r}=-0.44, \mathrm{p}<.001)$, as well as between $\mathrm{Bcl}-2$ and degree of anaplasia $(\mathrm{r}=-0.52, \mathrm{p}<.001)$. SAcFT metastases were associated with decreased anti-apoptotic protein expression $(r=-0.39, \mathrm{p}<.01)$ (Table 5$)$.

The correlation between Ki-67 and $\mathrm{p} 53$ expression $(\mathrm{p}<.05)$ has been established. Patients with high $\mathrm{p} 53$ expression ( $58.3 \%$ of cases) were predominant in the high Ki-67 expression group. There was a negative correlation between expression of Ki-67 and $\mathrm{Bcl}-2(\mathrm{p}<.05)$.

Cytoplasmic expression of VEGF was detected in both tumor
Table 5. Results of Bcl-2 expression study in SAcFT depending on prevalence, presence of lymphogenous metastases, and degree of malignancy

\begin{tabular}{lccrr}
\hline \multirow{2}{*}{ Evaluation's criteria } & \multicolumn{4}{c}{ No. of Bcl-2-positive tumor cases } \\
\cline { 2 - 5 } & 0 & $1+$ & $2+$ & $3+$ \\
\hline Disease stage according to FIGO classification & & & \\
I ( $n=23)$ & - & 1 & 4 & 18 \\
II $(n=16)$ & 3 & 2 & 5 & 6 \\
III $(n=27)$ & 8 & 4 & 9 & 6 \\
The presence of lesion in regional lymph nodes & & & \\
$\quad$ N0 $(n=47)$ & 2 & 5 & 12 & 28 \\
N1 $(n=19)$ & 9 & 2 & 6 & 2 \\
Degree of tumor differentiation & & & & \\
G1 $(n=10)$ & - & - & - & 100 \\
G2 $(n=23)$ & 3 & - & 5 & 15 \\
G3 $(n=33)$ & 8 & 7 & 13 & 5 \\
\hline
\end{tabular}

SAcFT, serous adenocarcinoma of the fallopian tubes; FIGO, International Federation of Gynecology and Obstetrics.

cells and vascular endothelium. Most patients had moderate or strong cytoplasmic signals in endothelial cells (87.9\%) and in more than $70 \%$ of tumor cells located diffusely in all fields of view (Fig. 2G, H). Only six cases (9.1\%) had weak and moderate focal expression of $10 \%-50 \%$. Focal weak cytoplasmic reaction, which was present in less than $10 \%$ of tumor cells and in the endothelium of single vessels, was observed in only two cases (3\%).

The angiogenic potential of PCFT depends on the degree of differentiation $(\mathrm{p}<.05)$ and clinical disease stage $(\mathrm{p}<.05)$. Moreover, all cases of regional lymph node metastases were accompanied by strong VEGF expression. This result may confirm that metastasis of PCFT depends on angiogenesis. In general, steroidnegative FT tumors were characterized by a higher level of VEGF expression. There was weak correlation between expression of VEGF and $\mathrm{p} 53(\mathrm{r}=0.25, \mathrm{p}<.05)$. There was no significant correlation between VEGF expression and the presence of $\mathrm{Ki}-67$ and $\mathrm{Bcl}-2$ receptors $(\mathrm{p}>.05)$.

\section{DISCUSSION}

Numerous scientific publications on PCFT include single observations of this disease. ${ }^{15,16}$ Patients with malignant FT neoplasms are typically older, which may be due to increased amount of secretory cells in older women. ${ }^{17,18}$ Morphologically, malignant epithelial tumors of the FT can be comprised of carcinomas of all cell types. In our research, the overwhelming majority of malignant neoplasms were SAcFT, which demonstrate a high degree of malignancy and very aggressive behavior.

The presence of steroid hormone receptors in FT tumors is a 
substantial indicator for the use of hormonal therapy. ${ }^{19}$ Conversely, steroid-negative tumors are contraindicated for hormone therapy. The medical literature includes sporadic reports on the use of hormonal therapy combined with cytostatics for treatment of FT neoplasia. ${ }^{20-22}$ Increased anaplasia and significant tumor spread are associated with decreased steroid-positive cells and an increased proportion of steroid-negative FT neoplasms. This can be explained by functional and phenotypic simplification of tumor cells with decreased ER and PR expression associated with tumor progression (increased tumor autonomy degree). Moreover, neoplasias with lymph node metastases expressed significantly less ER and PR than cases without lymph node metastases $(\mathrm{p}<.001)$. Our results demonstrate that the presence of steroid hormone receptors in SAcFT is an important prognostic biologic characteristic of these neoplasias. Reduced or lost expression of both $\mathrm{ER}$ and PR in FT tumors is associated with invasion, metastasis, and an adverse disease course.

The results of our research indicate that overexpression of HER 2/ neu is not typical for PCFT. In contrast to our data, overexpression of HER2/neu in neoplastic FT tissue has been demonstrated by some authors in $25.6 \%,{ }^{23} 31 \%,{ }^{24}$ and even $89 \%{ }^{25}$ of SAcFT. According to our results, we cannot recommend testing for this oncoprotein as a prognostic biomarker.
Immunohistochemistry demonstrated a mean Ki-67 of $55.0 \% \pm$ $12.2 \%$. Most FT tumors have a proliferation index of more than $60 \%(54.5 \%)$. PCFT has high proliferative activity, indicating an extremely aggressive disease course. In the presence of metastases, the level of Ki-67 expression can be considered an independent prognostic marker for $\mathrm{N}$-status in PCFT. This contributes to the allocation of certain women to the high-risk patient group.

The received data suggests that there is no direct dependency between a cell's steroid status and its ability to divide. This indicates that complex hormonal mechanisms contribute to proliferation. The significant increase in proliferative activity of PR cells may demonstrate the significant effect of progesterone on the ability of cells to divide.

In our study, $80.3 \%$ of SAcFT cases were p53-positive. p53 mutations were associated with tumor spread. In contrast to $\mathrm{p} 53,72.4 \%$ of cases expressed the anti-apoptotic $\mathrm{Bcl}-2$ protein in the first stages of the neoplastic process. Blockage of apoptosis likely occurs in one of two tumor growth stages via different mechanisms; in the early stages, $\mathrm{Bcl}-2$ is activated, while in the late stages, mutations in the TP53 gene occur. This results in the loss of functional qualities of the protein that it encodes. Exuberant amounts of mutant p53 and decreased wild-type p53 lead to suppression of the apoptosis blockade, which consequently

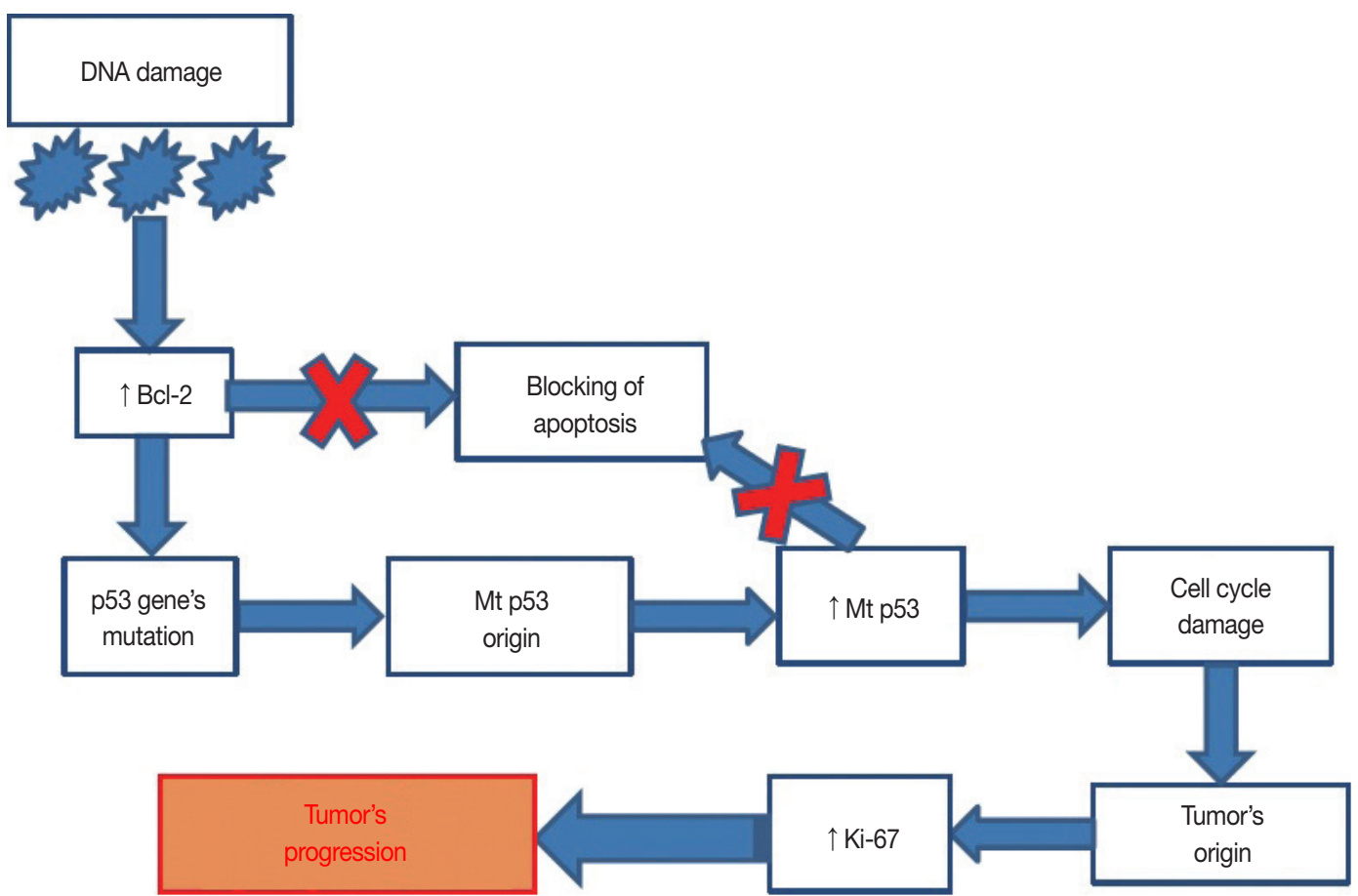

Fig. 3. Scheme mutant (mt) of p53 participation in carcinogenesis of primary cancer of the fallopian tubes. DNA damage and appearance of mt p53 proteins results in suppression of blocked apoptosis. Conversely, it also stimulates increased antiapoptotic Bcl-2 proteins, which enhance the inhibitory effect on apoptosis. This is manifested in altered cell cycle regulation. All of these events lead to increased proliferative tumor activity and progression of malignancy. 
increases cell proliferation. Cell division becomes uncontrolled and the malignant process actively progresses (Fig. 3).

The p53+ status of SAcFT correlates with a high degree of malignancy, significant tumor spread, metastases, and high proliferation. In other words, $\mathrm{p} 53+$ status can act as an independent prognostic factor for PCFT. In addition, our studies show that the $\mathrm{Bcl}-2+$ status of FT tumors correlates with positivity of steroid hormone receptors, low degree of anaplasia, and low proliferation. $\mathrm{Bcl}-2$ overexpression indicates more intense inhibition of apoptosis and should be accompanied by more aggressive tumor behavior. Nonetheless, according to our obtained data, Bcl-2 overexpression is a positive predictor for PCFT. This is likely due to a combination of $\mathrm{Bcl}-2$ and steroid hormone receptor expression since the $\mathrm{Bcl}-2$ gene is estrogen-dependent. ${ }^{26,27}$

FT tumors are characterized by robust angiogenesis. Sometimes, tumor cells can stimulate angiogenesis (angiogenetic activation) by forming and releasing angiogenetic factors (e.g., VEGFs) that stimulate endothelial cell proliferation and capillary growth. ${ }^{28,29}$ In our research, the majority of patients (87.9\%) had moderate or strong VEGF cytoplasmic expression in endothelial cells and in more than $70 \%$ of tumor cells were located diffusely in all fields of view. Accordingly, constant and intense angiogenesis in PCFT determines their fast growth and has adverse prognostic implications. We have also detected that the angiogenic potential of malignant FT tumors correlates with the degree of differentiation, clinical disease stage, negative ER/PR status, and $\mathrm{p} 53$-positive status $(\mathrm{p}<.05)$. All cases of metastasis in regional lymph nodes were accompanied by strong VEGF expression.

The results of our complex morphological study of PCFT demonstrate factors that should be considered when determining the strategy for treating patients with malignant FT tumors, including use of antihormonal therapy in cases of steroid positive tumors, adjuvant chemotherapy in cases with proapoptotic protein values, p53 higher than $10 \%$, proliferative activity more than $60 \%$, and use of anti-VEGF therapy in cases with high angiogenic potential. Our study was limited by a lack of data on patient lifestyle, which may be important, as it is in neoplastic processes in other female reproductive organs. ${ }^{30,31}$

In most cases, PCFT is serous adenocarcinoma. Neoplastic cells have high rates of expression for estrogen receptors (83.3\%), progesterone receptors $(62.1 \%), \mathrm{Ki}-67(55.0 \% \pm 12.2 \%), \mathrm{p} 53$ (80.3\%), Bcl-2 (81.8\%), and VEGF (87.9\%), which influence tumor aggressiveness. The use of complex morphologic (histological and immunohistochemical) study of postoperative material allows assessment of the degree of malignancy and tumor spread. This allows selection of appropriate therapeutic tactics for each individual case.

\section{ORCID}

Natalia Hyriavenko: https://orcid.org/0000-0002-9805-014X

Mykola Lyndin: https://orcid.org/0000-0003-4385-3903

Kateryna Sikora: https://orcid.org/0000-0002-9814-6512

Artem Piddubnyi: https://orcid.org/0000-0002-6508-0131

Ludmila Karpenko: https:/orcid.org/0000-0002-5274-7021

Olha Kravtsova: https://orcid.org/0000-0003-1393-8383

Dmytrii Hyriavenko: https://orcid.org/0000-0003-0223-9202

Olena Diachenko: https://orcid.org/0000-0001-6589-2191

Vladyslav Sikora: https://orcid.org/0000-0002-4147-6879

Anatolii Romaniuk: https:/orcid.org/0000-0003-2560-1382

\section{Author Contributions}

Conceptualization: NH, ML, VS, AR.

Data curation: NH, ML, KS, AP, LK, VS, OK.

Formal analysis: $\mathrm{NH}, \mathrm{DH}, \mathrm{OD}$.

Investigation: $\mathrm{NH}, \mathrm{ML}, \mathrm{KS}, \mathrm{AP}, \mathrm{LK}, \mathrm{OK}, \mathrm{VS}, \mathrm{DH}, \mathrm{OD}$.

Methodology: NH, ML, KS, AR, VS.

Project administration: NH, ML, VS, AR.

Resources: OK, KS, AR.

Software: AP, LK, DH.

Supervision: AR.

Validation: NH, ML, KS, AP, LK, OK, VS.

Visualization: $\mathrm{NH}, \mathrm{KS}, \mathrm{AP}, \mathrm{LK}, \mathrm{OK}$.

Writing—original draft: NH, ML, KS, AP, LK, OK, OD, VS.

Writing—review \& editing: NH, ML, AR.

\section{Conflicts of Interest}

The authors declare that they have no potential conflicts of interest.

\section{Acknowledgments}

The work was perfomed with the support of the research theme 'Development of the diagnosis method of the reproductive system organs tumors using CEACAMs' and 'Effectiveness of "liquid biopsy" and tissue biopsy in the diagnosis and treatment of malignant tumors.'

We thank Zolotarova Vera who helped in the conduction of immunohistochemical reactions.

\section{REFERENCES}

1. Jemal A, Bray F, Center MM, Ferlay J, Ward E, Forman D. Global 
cancer statistics. CA Cancer J Clin 2011; 61: 69-90.

2. Azodi M, Langer A, Jenison EL. Primary fallopian tube carcinoma with isolated torsion of involved tube. Eur J Gynaecol Oncol 2000; 21: 364-7.

3. Singhal P, Odunsi K, Rodabaugh K, Driscoll D, Lele S. Primary fallopian tube carcinoma: a retrospective clinicopathologic study. Eur J Gynaecol Oncol 2006; 27: 16-8.

4. Kalampokas E, Sofoudis C, Boutas I, Kalampokas T, Tourountous I. Primary fallopian tube carcinoma: a case report and mini-review of the literature. Eur J Gynaecol Oncol 2014; 35: 595-6.

5. Riska A, Leminen A. Updating on primary fallopian tube carcinoma. Acta Obstet Gynecol Scand 2007; 86: 1419-26.

6. Callahan MJ, Crum CP, Medeiros F, et al. Primary fallopian tube malignancies in BRCA-positive women undergoing surgery for ovarian cancer risk reduction. J Clin Oncol 2007; 25: 3985-90.

7. Kalampokas E, Kalampokas T, Tourountous I. Primary fallopian tube carcinoma. Eur J Obstet Gynecol Reprod Biol 2013; 169: 155-61.

8. Kessler M, Fotopoulou C, Meyer T. The molecular fingerprint of high grade serous ovarian cancer reflects its fallopian tube origin. Int J Mol Sci 2013; 14: 6571-96.

9. Reade CJ, McVey RM, Tone AA, et al. The fallopian tube as the origin of high grade serous ovarian cancer: review of a paradigm shift. J Obstet Gynaecol Can 2014; 36: 133-40.

10. Kim J, Coffey DM, Creighton CJ, Yu Z, Hawkins SM, Matzuk MM. High-grade serous ovarian cancer arises from fallopian tube in a mouse model. Proc Natl Acad Sci U S A 2012; 109: 3921-6.

11. Przybycin CG, Kurman RJ, Ronnett BM, Shih IM, Vang R. Are all pelvic (nonuterine) serous carcinomas of tubal origin? Am J Surg Pathol 2010; 34: 1407-16.

12. Riska A, Leminen A, Pukkala E. Sociodemographic determinants of incidence of primary fallopian tube carcinoma, Finland 1953-97. Int J Cancer 2003; 104: 643-5.

13. Potapov S, Sidorenko R, Galata D, Stratiy N, Gargin V. Peculiarities of catenin activity in the embryonal testicular carcinoma. Georgian Med News 2016; (261): 68-73.

14. Romaniuk A, Lyndin M, Smiyanov V, Sikora V, Rieznik A, Kuzenko $Y$, et al. Primary multiple tumor with affection of the thyroid gland, uterus, urinary bladder, mammary gland and other organs. Pathol Res Pract 2017; 213: 574-9.

15. Oliveira C, Duarte H, Bartosch C, Fernandes D. Small fallopian tube carcinoma with extensive upper abdominal dissemination: a case report. J Med Case Rep 2013; 7: 252.

16. Pectasides D, Pectasides E, Papaxoinis G, et al. Primary fallopian tube carcinoma: results of a retrospective analysis of 64 patients.
Gynecol Oncol 2009; 115: 97-101.

17. Wang Y, Li L, Wang Y, Tang SN, Zheng W. Fallopian tube secretory cell expansion: a sensitive biomarker for ovarian serous carcinogenesis. Am J Transl Res 2015; 7: 2082-90.

18. Wang Y, Wang Y, Li D, et al. IMP3 signatures of fallopian tube: a risk for pelvic serous cancers. J Hematol Oncol 2014; 7 : 49.

19. Farooq S, Tasleem R, Nazir N, Reshi R, Hassan Z. Histopathological pattern of ovarian neoplasms and estrogen and progesterone receptor expression in primary epithelial tumours and their histopathological correlation. Int J Curr Res Rev 2013; 5: 70-7.

20. Rose PG, Piver MS, Tsukada Y. Fallopian tube cancer. The Roswell Park experience. Cancer 1990; 66: 2661-7.

21. Rosen AC, Reiner A, Klein M, et al. Prognostic factors in primary fallopian tube carcinoma. Austrian Cooperative Study Group for Fallopian Tube Carcinoma. Gynecol Oncol 1994; 53: 307-13.

22. Thomas C, Gustafsson JÅ. The different roles of ER subtypes in cancer biology and therapy. Nat Rev Cancer 2011; 11: 597-608.

23. Lacy MQ, Hartmann LC, Keeney GL, et al. c-erbB-2 and p53 expression in fallopian tube carcinoma. Cancer 1995; 75: 2891-6.

24. Alvarado-Cabrero I, Kiyokawa T, Piña P, Valencia-Cedillo R, Santiago-Payán H, Stolnicu S. HER2/neu, p53, MIB1 and PAX8 immunoexpression in primary serous fallopian tube carcinomas. Rev Esp Patol 2016; 49: 219-25.

25. Chung TK, Cheung TH, To KF, Wong YF. Overexpression of p53 and HER-2/neu and c-myc in primary fallopian tube carcinoma. Gynecol Obstet Invest 2000; 49: 47-51.

26. Dawson SJ, Makretsov N, Blows FM, et al. BCL2 in breast cancer: a favourable prognostic marker across molecular subtypes and independent of adjuvant therapy received. Br J Cancer 2010; 103: 66875.

27. Romaniuk A, Lyndin M. Immune microenvironment as a factor of breast cancer progression. Diagn Pathol 2015; 10: 79.

28. Carmeliet P. VEGF as a key mediator of angiogenesis in cancer. Oncology 2005; 69 Suppl 3: 4-10.

29. Lichtenberger BM, Tan PK, Niederleithner H, Ferrara N, Petzelbauer $\mathrm{P}$, Sibilia M. Autocrine VEGF signaling synergizes with EGFR in tumor cells to promote epithelial cancer development. Cell 2010; 140: $268-79$.

30. Lytvynenko M, Bocharova T, Zhelezniakova N, Narbutova T, Gargin V. Cervical transformation in alcohol abuse patients. Georgian Med News 2017; (271): $12-7$.

31. Lytvynenko M, Shkolnikov V, Bocharova T, Sychova L, Gargin V. Peculiarities of proliferative activity of cervical squamous cancer in HIV infection. Georgian Med News 2017; (270): 10-5. 